\title{
Kamu Kurumlarında Toplam Kalite Yönetimi Uygulamalarının Deming Yönetim Metodu ile Analizi
}

\begin{abstract}
Esra Çapacıoğlu' (1)
Necdet Özçakar ${ }^{2}$

Onur Çetin ${ }^{3}$

Öz

Toplam Kalite Yönetimi (TKY) yönetim düşüncesindeki en önemli değişimlerden biri olarak görülebilir. Son yıllarda kamu sektöründe yönetim felsefesi de değişmiştir ve TKY bu değişimin de önemli bir parçası haline gelmiştir. TKY kamu sektörü için tasarlanmış olmadığından kamu sektöründe TKY uygulanması da özel sektördeki kadar kolay değildir. Bu nedenle kamu kurumları, uygulamak için en uygun TKY yaklaşımlarını araştırmaktadırlar. TKY yaklaşımlarından birisi olan Deming Yönetim Metodu TKY değişkenleri arasında bazı ilişkileri öngören model önermektedir. Bu modele göre en sonda müşteri tatmini bulunmaktadır ve TKY değişkenleri arasındaki ilişkiler, sonunda bir başka TKY değişkeni olan müşteri tatminini etkilemektedir. Bu çalışmanın temel amacı kamu sektöründe TKY değişkenleri ve müşteri tatmini arasındaki ilişkiyi Deming Yönetim Metodu açısından incelenmesidir. Bunun için dört kamu kurumunun çalışanlarından anket yöntemi ile veri toplanmıştr. Kurumlardan birisi ISO belgesine sahipken tüm kurumlarda belirli ölçüde kalite uygulamaları gerçekleştirilmektedir. Sonuçlara göre model tarafindan önerilen pek çok ilişki desteklenmiştir. TKY değişkenlerinin kurumlara ve çalışanların demografik özelliklerine göre nasıl farklılaştğı ve TKY ile ilgili çalışanların tutumları da analiz edilmiştir. Elde edilen bulgular literatür ile uyumludur.
\end{abstract}

\author{
Anahtar Kelimeler \\ Kamu sektörü • Toplam kalite yönetimi • Deming Yönetim Metodu • ISO • Müşteri tatmini
}

\section{An Analysis of Total Quality Management Practices in Public Agencies Using the Deming Management Method}

\section{Abstract}

Total Quality Management (TQM) can be regarded as one of the most important changes in management thought. Management philosophy of public agencies has been changing in last decades and TQM has become an important part of this change as well. As TQM is originally designed for private sector, implementation of TQM for public sector is not as easy as it is in private sector. For this reason, private agencies have been seeking appropriate TQM approaches for themselves. Deming Management Method which supposes a model including certain relationships between TQM variables is one of these approaches. According to this model relationships between TQM variables consequently affects customer satisfaction which is a TQM variable as well. This research mainly aims to seek the relationships between quality management practices and customer satisfaction in public sector from the point of view of Deming Management Method. A survey is conducted to employees of four public agencies. All agencies have quality management practices to some extent but only one of them has ISO certification. According to the results, most of the relationships supposed by the model is supported. The differentiation of TQM variables among agencies and among demographic characteristics of employee's is also analyzed. Attitudes of employees towards TQM are analyzed as well. The findings are consistent with the literature.

\section{Keywords}

Public sector • Total quality management $\bullet$ Deming Managment Method •ISO • Customer satisfaction

1 Sorumlu Yazar: Esra Çapacıoğlu Arel Üniversitesi, Sosyal Bilimler Enstitüsü, İstanbul, Türkiye.

Eposta: capaciesra92@outlook.com

2 Necdet Özçakar (Prof. Dr.), İstanbul Üniversitesi, İşletme Fakültesi, İstanbul, Türkiye. Eposta: necdet@istanbul.edu.tr

3 Onur Çetin (Dr. Öğr. Üyesi), Trakya Üniversitesi, İ̧letme ve İktisadi Bilimler Fakültesi, İ̧letme Bölümü, İstanbul, Türkiye.

Eposta: onurcetin@trakya.edu.tr

Attf: Çapacıoğlu, E., Özçakar, N. ve Çetin, O. (2018). Kamu kurumlarında toplam kalite yönetimi ile müşteri tatmini ilişkisi. Istanbul Management Journal, 29(85), 107-125. http://dx.doi.org/10.26650/imj.2018.29.85.0008 


\section{Extended Summary}

\section{Background}

The Total Quality Management (TQM) can be regarded as one of the most important changes in management thought. The philosophy of public agency management has been changing over the last decades, and TQM has become an important part of this change as well. As TQM is originally planned for the private sector, implementation of TQM in the public sector is not as easy as it is in private sector. Some researchers assert that it is difficult to implement TQM in the public sector because it is not appropriate for this sector (Morgan and Murgatroyd, 1994; Madsen, 1995). For this reason, private agencies have been seeking appropriate TQM approaches for themselves.

\section{Purpose}

This research aims to implement the Deming Management Method in the Turkish public sector and to analyze the effects of TQM practices on customer satisfaction.

\section{Method}

The Deming Management Method is one of the approaches to be used in supposing a path analysis model including certain relationships among the TQM variables. According to this model, relationships among the TQM variables consequently affect customer satisfaction, which is also a TQM variable (Anderson et al., 1994). The model has been tested in the private as well as in the public sector. It is however used only partially in the Turkish public sector and has not been used appropriately in the Turkish public sector path analysis so far. A survey was conducted among employees of four public agencies. All agencies have quality management practices to some extent but only one of them has an ISO certification. Datas were obtained through a questionnaire which consists of three parts. The first part contains a TQM scale including seven variables (leadership, continuous improvement, employee fulfillment, learning, process management, teamwork, and customer satisfaction) each measured on a 5-point Likert scale. In the second part of the survey, respondents were asked about their familiarity with TQM and TQM practices prevalent in the agency. Additionally, attitudes of the respondents toward TQM were examined in the second part. The last part was regarding demographic variables.

\section{Findings}

Confirmatory Factor Analysis was conducted and fit indices showed good or acceptable form which means the factors obtained matched with the variables in the theoretical model. The structural equation model presented good or acceptable results 
regarding fit indices. According to the results, most of the relationships supposed by the model are supported. However, the path between employee satisfaction and customer satisfaction was not supported. The results were compared with the literature and it was observed that the findings are consistent with the literature.

All of the variables in the structural regression model had scores between three and four which means that six practices were carried out to some extent and customer satisfaction was created. The results indicate that in an average $41 \%$ of respondents had attended quality practices in their agencies while $53 \%$ of them had completed TQM training in their agencies. Besides this, 83\% of respondents believe that TQM is required to produce high quality services.

The differentiation of TQM variables among agencies and demographic characteristics of employees was also analyzed. No difference was observed among scores of the variables across the four agencies. This means that the perceptions of the respondents in the agency with regard to ISO certification are not statistically different from those of the respondents of other agencies. Attitudes of employees towards TQM were analyzed as well.

\section{Conclusions}

The public sector has made significant efforts for improving customer satisfaction. This research demonstrates that the Deming Management Method can be used as a way of improving customer satisfaction in the Turkish public sector. The model can be used in a larger sample to generalize the results. 
Toplam Kalite Yönetiminin (TKY) özel sektördeki varlığı gerek akademik anlamda gerekse pratik uygulamalar anlamında çok eskilere dayanmaktadır. Özel sektör açısından TKY günümüzde bir zorunluluk olarak görülmektedir. Kamu sektörü aç1sından bakıldığında ise toplumsal değişimin şartlarına uyum sağlamak ve mutlak olarak, süreklilik arz edecek şekilde toplumun beklentilerine en yüksek düzeyli olarak cevap verebilmek adına TKY üzerinde daha çok odaklanması gerektiği belirtilmektedir (Güller, 2008, s: 27). TKY geçen zaman ve değişen evrensel yönetim şartları doğrultusunda, kamunun ister istemez ihtiyaç duyduğu faaliyetlerden biri haline gelmektedir. Özellikle gelişmiş ülkelerde devletin daha fonksiyonel olarak hareket etme arzusunun bulunduğu günümüzde TKY, kamu yönetimlerinin üzerine eğildiği hususlardandır (Peker, 1996, s: 54).

\section{Kamuda Toplam Kalite Yönetimi}

Kamu sektöründe TKY uygulamaları gelişmiş ülkelerce hızla benimsenerek uygulamaya konmuştur. Bunun da ötesinde, söz konusu ülkelerin bir kısmı, kamuda toplam kalite yönetimi uygulamalarının birer zorunluluk halini alması adına süreci tam anlamı ile kanunlaştırmışlardır. ABD hükümeti oluşturduğu "Federal Kalite Kurumu" ile birlikte konuya anayasal ve kanuni bir boyut katmıştır (Balc1, 2005b, s: 24). Benzer şekilde İngiltere'de de ABD'de olduğu gibi TKY, kamuda politika belirlemede etkili olmuştur (Morgan ve Murgatroyd, 1994, s: 42)

\section{Kamuda Toplam Kalite Yönetimini Zorunlu Kılan Unsurlar}

Özel sektörün toplam kalite yönetimi ile elde etmiş olduğu başarı ve karlılık oranları göz önünde bulundurulduğunda, kamunun da sürecin parçası olması adına genel olarak uygun bir yapının oluşturulduğu görülmektedir. Fakat bu yapının oluşmasında, kamunun kendi inisiyatifi ve tercihlerinden çok çevresel bir baskının varlığından, bir zorunluluktan bahsetmek mümkündür. Buna göre kamuda TKY'yi zorunlu k1lan unsurları aşağıdaki gibi sıralamak mümkündür (Balc1, 2005a: 199-200):

- Değişimin zorunluluğu: Kamu yönetimlerinin çoğunlukla geçmişten gelen hiyerarşik alg1 ile hareket ettikleri düşünüldüğünde aslında ortaya çıkan tablo kalıplaşmış sistemlerin fazlası ile benimsenmiş olmasıdır. Fakat günümüzde toplum devletten daha güçlü hale gelmekte ve daha fazla beklenti içinde olmaktadır.

- Toplumsal çekinceler: Özel sektörden mümkün olduğunca yüksek kaliteli hizmet alma konusunda alışkanlıkları bulunan vatandaşlar için aynı beklenti, zaman içerisinde kamu hizmetleri üzerinde de oluşmaktadır.

• Özelleştirme baskısı: Özelleştirme ile kamunun yapısının küçültülerek kamunun kendisi için daha fazla odaklanma gerektiren konular üzerinde sistematik olarak ha- 
reket etmesini öngören toplumsal değişimler söz konusudur. Buna göre vatandaşlar, kamu kurumlarının uzmanlık alanlarında daha kaliteli hizmet vermesi gerektiğine inanmaktadirlar.

- Finansal sebepler: Yoğun ve fazlası ile bürokrasi gerektiren işlemlerin kamu üzerine yüklemiş olduğu finansal ağırlık sistemin hantallaşmasına ve son derece yavaş, bir o kadar da fazla maliyetli olmasına sebebiyet vermektedir. Bu nedenle TKY odakl1 olarak gerçekleştirilecek olan değişim ve modernlik içeren atılımlar kamu harcamalarının maliyetini düşürecek, daha az maliyet ile daha fazla işin gerçekleştirilmesine olanak taniyacaktır.

\section{Kamuda Toplam Kalite Yönetimi İlkeleri}

TKY çeşitli uygulamalardan oluşan bir bütündür. TKY'nin uygulamaları TKY'nin ilkeleri olarak da ifade edilebilir. Dean ve Bowen (1994) TKY'nin TKY'nin, müşteri odaklılık, takım çalışması ve sürekli gelişme olmak üzere üç ilkesi olduğundan bahsederken, Anderson vd. (1994) ise Deming Yönetim Metoduna göre toplam yedi ilke belirlemiştir. Bu ilkeler; vizyoner liderlik, işbirlikleri, öğrenme, süreç yönetimi, sürekli gelişme, çalışan tatmini ve müşteri tatmini olarak sıralanabilir.

Kamuda Toplam Kalite Yönetimi İlkelerini sırası ile şu şekilde değerlendirmek mümkündür:

- Liderlik: TKY'nin gözetildiği bir kamu kurumunda öncelik, liderlik mekanizmasının algısının değişmesidir. Kararların gizlilik ile alınması ve fikirlerin çevre ile istişare edilerek alınmaması, sistemin önündeki ciddi ve tehlikeli engellerden biri olarak görülebilmektedir (Özalsalmanlı, 2005, s. 145). Liderler paylaşımcı olmalı ve bu sayede de çalışanları ile liderliğin avantajlarını paylaşmaları gerekmektedir.

- Müşteri Tatmini: Kamu sektöründe müşteri tatmini özel sektöre göre daha farklıdır. Aslında vatandaşın kamuda daha etkin ve daha fazla hakkı bulunan bir aktör olması ona karşı sergilenecek tavrın daha olumlu olması gerektiği konusunda net bir görüntü ortaya koymaktadır. Vatandaşlar, kamu hizmetlerini sorgulayan, ondan sürekli olarak faydalanan ve onun gelişmesi adına da fikir beyanında bulunan aktif bir vatandaş konumunda bulunmaktadır (Çukurçayır ve Sipahi, 2003, ss. 42).

- İş Birlikleri: Kamu açısından, tıpkı özel sektörde olduğu lider konumundaki yöneticilerin çalışanlarını cesaretlendirmeleri ve ekip halinde hareket etme konusunda teşvik etmeleri büyük önem taşımaktadır. Buna göre çalışanlar birbirlerine daha fazla yaklaşırlarken ortaya koydukları toplu performans da yükselmektedir. Vatandaşlara karşı sorumlulukların tam olarak yerine getirilebilmesi adına ekip halinde yürütülecek çalışmalar hizmetlere zengin bir içerik kazandırabilecektir. (Kağnıcıoğlu, 2002, s. 87). 
- Öğrenme: Kamu kuruluşlarında, toplam kalite yönetimi adına çalışan eğitimine ihtiyaç duyulan noktalardan bir diğeri de çalışanların kurum içi eğitimi ile birlikte kuruma dair performanslarının da arttırılmasıdır. Çalışanların hem kendi gelişimleri hem kurumlarına daha verimli hizmet etmeleri hem de dolayısıyla vatandaşlara nitelikli hizmet edebilmeleri bu eğitim süreçleri ile mümkün olmaktadır (Ekinci, 2008, s.181).

- Çalışanların İş Tatmini: İş tatmini, işletme yönetimlerinin, çalışanlarından daha fazla verim elde etmek adına tetikleyici, destekleyici, verimlilik arttırıcı ve ilerleyen zaman zarfı için bir bağl1lık oluşturacak türdeki unsurların tümü olarak değerlendirilmektedir (Çetin 2007: 92).

- Sürekli Gelişme: Özellikle vatandaşların kamuya ve kamu kurumlarına güvenlerinin tahsisi açısından gelişim ve değişim odaklı hareket etme konusunda sürekli olarak adımlar atılmak durumundadır. Kamudaki belki de en önemli sorun, geliştirme ve iyileştirmeye dayalı adımların atılması konusunda, kökten bir değişimin yaşanmasına dair endişe ve çekinceler yer almaktadır. Bu nedenle kamuda yöneticiler ve çalışanlar, değişim ile konumlarını kaybedebilecekleri endişesi ile süreci olumlu şekilde değerlendirmemektedirler (Balc1, 2005, s. 206).

- Süreç Yönetimi: Kamu kurumlarındaki temel sorunların başında, çalışanların ve ortaya konan hizmetin yeterli düzeyde değerlendirilmemesi ve böylelikle de hizmete dair yeterli performans verisi elde edilememesi söz konusudur. Bu noktada önemli olan hem performans değerlendirmesi hem de performansın arttırılmasına yönelik olan programların kamu çalışanları üzerinde uygulanmasıdır. Bunun yanı sıra performans odaklı verilerin değerlendirilmesi konusunda şeffaf olunması ve elde edilen verilerin kamu çalışanları ile paylaşılması gerekmektedir (Özçakar, 2010, s. 110).

\section{Kamuda Toplam Kalite Yönetimine Dair Karşılaşılabilecek Sorunlar}

Kamunun sistematik olarak yeniliklere ve gelişime özel sektörden daha kapalı olması sebebi ile modern döneme ait olan birçok uygulama ya daha geç kamuya uyarlanmakta ya da hiçbir zaman kamu ile ilintili hale getirilememektedir. Böylelikle kamu yönetimi, kendi kalıplaşmış sistemi üzerinden hareket etmeyi kendisine bir yöntem olarak belirlerken yenilikleri çoğunlukla geri planda bırakmayı tercih etmiştir. Bu nedenle de toplam kalite yönetimi, kamu yönetimi açısından kimi zaman çeşitli sorunları beraberinde getirebilmektedir. Morgan ve Murgatroyd (1994) TKY'nin kamu sektörü־nün doğasından ve çalışma kültüründen kaynaklanan nedenler ile başarılı bir şekilde uygulanamayacağını belirtmektedir. Madsen de (1995) TKY'nin kamu sektöründe uygulanmasının önünde bazı zorlukların olduğundan bahsetmektedir. Bunlar; politik güç, ekonomik kontrol, grup etkileri ve örgüt kültürü gibi engellerin olarak sıralanabilir. Powell, (1995) benzer şekilde TKY uygulamalarının kamu 
personeli tarafından gereksiz görülerek TKY'ye karşı direç oluştuğunu belirtmektedir. Bunun yanında iş güvencesinin olmadığı özel sektörde başarı ile uygulanan TKY'nin iş güvencesinin olduğu kamu sektöründe aynı başarıyı elde edip edemeyeceği bir diğer tartışma konusudur.

Kamuda TKY uygulamasında ortaya çıkacak olası sorunlar aşağıdaki gibi sıralanabilir (Balc1, 2005: ss. 201-203);

- Müşteri tanımının tam olarak yapılmaması,

- $\quad$ Kural ve kanunlara uyma gerekliliği,

- Kamunun çoğu hizmette tekel olması,

- Bürokrasinin girdi-çıktı sistemi üzerindeki etkisi.

Acar ve Sevinç (2013) ise TKY'nin kamuda uygulanmasının önündeki sorunların ikiye ayrıldığını, ilk sorun grubunun kamu sektörüne özel olmayan ve TKY ile ilgili olan genel sorunlar olduğunu, ikinci grubun ise kamu sektörüne özel sorunlar olduğunu belirtmektedir. Kamu sektörüne özel sorunlar aşağıdaki gibi sıralanmıştır;

- Kamu sektörünün değişime direnç göstermesi,

- Başarı kriterinin belirsiz olması,

- Kurum yöneticisinin insiyatif kullanma şansının az olması,

- Büyüklük,

- Belirsizlik,

- Çıkar gruplarının etkisi.

- $\quad$ Çıktı miktarının mı ve kalitesinin mi daha önemli olduğu ikilemi.

Genel olarak kamunun toplam kalite yönetimine alışmak ve onu uygulamak noktasında çeşitli sorunları bulunmaktadır. Bu sorunların temelinde, kamunun kendi alışmış olduğu sistemin dişına çıkmak istememesinin büyük bir etkisi bulunmaktadır. Bunun yanı sıra kamunun dünya genelinde yenilikleri çok geriden takip etmesi ve toplumsal baskılar ile çoğunlukla süreçlerin değişmesi kamunun halen atması gereken çok sayıda adımın olduğunu göstermektedir.

\section{Kamu Kurumlarında TKY ile İlgili Literatür}

Kamu sektörü ve TKY ile ilgili genişbir yabancı literatür bulunmaktadır. Kamu sektörünün genelde hizmet sektörü olması dolayısı ile öncelikle TKY'nin hizmet sektörüne uygunluğu tartışılmıştır. Bu konuda TKY'nin hizmet sektöründe de başar1lı sonuçları verebildiğine dair çalışmalar var iken (Hasan ve Kerr, 2003) aksi yönde de çalışmalar da bulunmaktadır (Boyne ve Walker, 2002). Hsieh Chou ve Chen (2002) kamu kurumunda gerçekleştirdikleri araştırmada yöneticilerin TKY'nin temel unsularından olan iş standardizasyonunun algılanan hizmet kalitesi ile ilişkili olduğu gözlenmiştir. Scharitzer ve Korunka (2010) kamuda TKY uygulaması sürecinin çal1- 
şanlar ve müşteriler açısından farklı sonuçlarının olabileceğinin, müşteriler açısından sonuçların olumlu iken çalışanlar açısından sonuçların daha karmaşık olabileceğinden bahsetmektedir. Chang Chiu ve Chen (2010) gerçekleştirdikleri çalışmada kamu kurumlarında TKY uygulamalarının çalş̧an tatminine ve sadakatine etkisini incelemişlerdir. Sonuç olarak TKY uygulamalarının çalışan tatmini ile ilişkili olduğunu belirtmiş̧lerdir. Fisher vd. (2005) daha önce Anderson vd.(1994) tarafindan teorik yol analizi modeli oluşturulan ve daha sonra Anderson vd. (1995) tarafindan imalat sektöründe test edilen Deming Yönetim Metodu isimli modeli imalat hizmet ve kamu sektörünü içerecek şekilde daha geniş bir örneklem ile test etmiştir.

Yerli literatürde kamuda TKY ilgili çalışmalar çoğunlukla sağlık sektöründe (Ayaz ve Soykan, 2002; Aslantekin vd, 2007; Can, 2008; Yaş, 2009; Yunus vd., 2016; Kazan vd., 2017) ve eğitim sektöründe yoğunlaşmıştır (Dağl1, 2014; Butün ve Aslanargun, 2016; Aslan, 2017). Bu iki sektördeki çalışmalara pek çok örnek verilebilir. Sağlik ve eğitim sektörleri dışında kamu kurumlarında TKY uygulamaları ile ilgili yapılan ampirik araştırmaların sayısı ise daha sınırlıdır (Üstüner ve Coşkun, 2004; Özçakar, 2010, Çetin ve Özçakar, 2014).

\section{Yöntem}

Bu bölümde araştırmanın amacı, modeli hipotezleri, örneklemi yer almaktadır.

\section{Araştırmanın Amacı}

Araştırma Toplam Kalite Yönetimi (TKY) kavramının kamu kurumlarında incelenmesi ile ilgilidir. Araştırmanın amacı TKY uygulamaları ile performans kriteri olan müşteri tatmini arasındaki ilişkileri incelemektir. Bu amaca ulaşmak için Anderson vd. (1994), tarafindan oluşturulan ve Deming Yönetim Metodu adı verilen model kullanılmıştır. Bu yol analizi modeli farklı araştırmacılarca test edilmiş olsa da (Anderson vd., 1995, Grandzol ve Gershon, 1998; Barfield vd., 2005) Türkiye'deki kamu kurumlarında test edilmemiştir. Bu araştırmanın temel amacı, bu modelin kullanılarak Türkiye'de kamu sektöründe TKY ile ilgili değişkenler arasındaki ilişkilerin ve dolayısı ile bu değişkenler ile müşteri tatmini ile ilişkisinin yapısal regresyon modeli ile analiz edilmesidir.

Araştırmanın bir diğer amacı TKY ile ilgili algılamaların kurumlara ve çalışanların demografik özelliklerine göre farklılaşıp farklılaşmadığının belirlenmesidir.

Daha önce belirtildiği şekilde (Powell, 1995) kamu sektöründe TKY'nin gereksiz bulunması ya da ideolojik bulunması gibi bir durum olabilmektedir. Bu durum Türkiye kamu sektörü için Üstüner ve Coşkun (2004) ve Çetin ve Özçakar (2014) tarafından araştırılmıştır. Araştırmanın üçüncü amacı TKY'nin gerekli görülme durumunun 
kurumda kalite ile ilgili eğitim almak veya kurumda kalite çalışmalarına katılmakla ilişkili olup olmadığının analiz edilmesidir.

\section{Araştırmanın Modeli ve Hipotezleri}

Araştırma amaçları doğrultusunda Anderson vd., 1995, Grandzol ve Gershon, 1998; Barfield vd., 2005 tarafından oluşturulan yol analizi modelinin, yapısal regresyon modeli oluşturulmuştur ve bu model Şekil 1.'de görülmektedir. Buna göre aşağıdaki hipotezler oluşturulmuştur. Tüm hipotezler için yokluk hipotezleri ilişki yoktur veya farklılık yoktur şeklindedir.

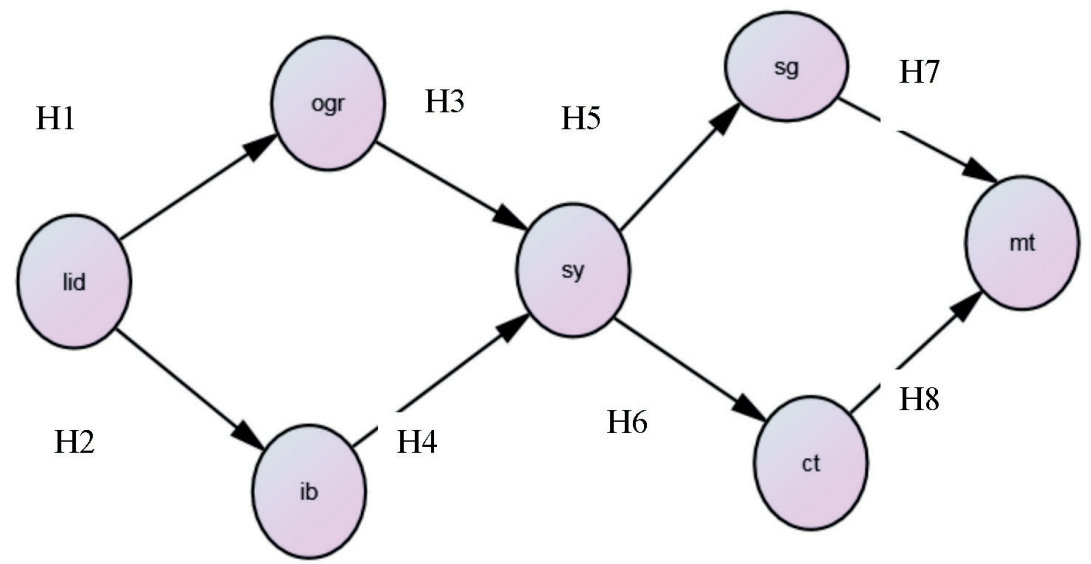

Şekil 1. Araştırma Modeli

Buna göre araştırma hipotezleri aşağıdaki gibidir.

$\mathrm{H}_{1}$ :Liderlik ile öğrenme arasında ilişki vardır.

$\mathrm{H}_{2}$ :Liderlik ile işbirlikleri arasında ilişki vardır.

$\mathrm{H}_{3}$ : Öğrenme ile süreç yönetimi arasında ilişki vardır.

$\mathrm{H}_{4}$ : İşbirlikleri ile süreç yönetimi arasında ilişki vardır.

$\mathrm{H}_{5}$ : Süreç yönetimi ile sürekli gelişme arasında ilişki vardır

$\mathrm{H}_{6}$ : Süreç yönetimi ile çalışan tatmini arasında ilişki vardır

$\mathrm{H}_{7}$ : Sürekli gelişme ile müşteri tatmini arasında ilişki vardır

$\mathrm{H}_{8}$ : Çalışan tatmini ile müşteri tatmini arasında ilişki vardır

Araştırmanın diğer amacı doğrultusunda TKY ile ilgili uygulamaların farklı kurumlarda farklı algılanıp algılanmadığı araştırılmıştır. Kurumların ve departmanların 
kalite yönetimi açısından farklı yapıda olması nedeni ile kurumlarda TKY ile ilgili uygulamaların farklılaşacağı düşünülmektedir. Bu nedenle $\mathrm{H}_{9}$ oluşturulmuştur.

$\mathrm{H}_{9}$ : Farklı kurumlarda çalışan cevaplayıcıların TKY faaliyetlerini algılamaları arasında çalıştıkları kurum açısından bir farklılık vardır.

Farklı pozisyonlarda çalışan katılımcılar arasında da TKY faaliyetlerinin algılanması açısından bir farklılık olacağı öngörülmektedir. Bu nedenle $\mathrm{H}_{10}$ oluşturulmuştur.

$\mathrm{H}_{10}$ : Farklı kurumlarda çalışan cevaplayıcıların TKY faaliyetlerini algılamaları arasında çalıştıkları pozisyon açısından bir farklı1ık vardır.

Araştırmanın üçüncü amacı doğrultusunda TKY'nin kaliteli hizmet vermek için gerekliliği konusundaki düşünce ile kurumda TKY ile ilgili eğitim almış olmak ve kalite ile ilgili çalışmalara katılıp katılmamış olmak arasında bir ilişki olup olmadığının incelenmesi amacı ile aşağıdaki hipotezler oluşturulmuştur.

$\mathrm{H}_{11}$ : TKY ile ilgili eğitim almış olmak ile TKY'yi kaliteli hizmet verebil $\neg$ mek için gerekli olarak algılamak arasında anlamlı bir ilişki vardır.

$\mathrm{H}_{12}$ : Kurumda kalite ile ilgili çalışmalara katılmış olmak ile TKY'nin kaliteli hizmet verebilmek için gerekli olduğunu düşünüp düşünmeme arasında anlamlı bir ilişki bulunmaktadır.

\section{Anakütle ve Örneklem}

Araştırma dört adet kamu kurumunda gerçekleştirilmiştir. Araştırmanın gerçekleştirildiği kurumlar kalite uygulamalarının gerçekleştirildiği kamu kurumları arasından belirlenmiştir. Her kurum kalite ile ilgili çeşitli uygulamalarda bulunduğundan, kurum içinde farklı departmanlarda ve alt departmanlarda ve pozisyonlarda kalite uygulamaları ile ilgili farklı algılamaların olması beklenmektedir. Her kurumda her departmana anket uygulanmasına dikkat edilmiş, departmanlar içinde anketler tesadüfi olarak uygulanmıştır. Toplamda elde edilen kullanılabilir anket sayısı 187 adettir.

İncelenen ilk kamu kurumu (Kurum1) Genel Müdürlük seviyesinde bankacılık alanında hizmet vermektedir. Kurum1'de TKY ile ilgili çalışmalar yapıldığ 1 üst yönetimce belirtmektedir. Kurum1, ISO 9001 ve ISO 27001 belgesine sahiptir ve kalite ile ilgili 2013 yılından bu yana çalışmalar yapılmaktadır. Kurumda TKY hakkında eğitimler de verilmektedir. Diğer kurumlar ile kıyaslandığında TKY uygulamaya en yakın kurumdur. Bu kurumda 150 çalışan vardır ve elde edilen kullanılabilir anket say1s1 88'dir. İkinci kamu kurumu (Kurum2) Genel Müdürlük seviyesinde vergi hizmetleri alanında hizmet veren bir kamu kuruluşudur ve kalite ile ilgili çeşitli uygu- 
lamalar gerçekleştirilmektedir. Kurumda verilen ekip çalışması eğitimleri, müşteri memnuniyeti eğitimleri gibi eğitimler bu uygulamalara örnek olarak verilebilir. Kurumda çalışan sayısı 110 iken elde edilen kullanılabilir anket sayısı 51'dir.

Üçüncü kamu kurumu (Kurum3) Genel Müdürlük seviyesinde eğitim ve hizmet alanında hizmet veren bir kamu kuruluşudur. Kurum 3, ISO 9001 belgesine sahip değildir ancak kalite ile ilgili eğitimler verilmektedir. 3 kodlu kamu kurumunda 45 çalışan bulunmakla beraber bu kurumdan elde edilen kullanılabilir anket sayısı 20'dir.

Dördüncü kamu kurumu, (Kurum4) haberleşme ve ulaşım alanında hizmet veren bir kamu kuruluşudur. Bu kurumda müşteri odakl11ık eğitimi verilmiştir. Kurumda 60 çalışan bulunmakla beraber elde edilen kullanılabilir anket sayısı 28'dir.

\section{Veri Toplama Yöntemi ve Aracı}

Araştırmada yüz yüze anket yöntemi ile veri toplanmıştır. Anketler kamu kurumlarında çalışan personele uygulanmıştır. Anket formu üç bölümden oluşmaktadır. Birinci bölümde, Anderson vd.'nin (1994) oluşturduğu modele göre Grandzol ve Gershon (1998) tarafından geliştirilen ve Çetin ve Özçakar (2014) tarafından Türkçe'ye uyarlanan ve TKY ile ilgili faaliyetleri ölçmeyi amaçlayan TKY ölçeği yer almaktadır. Ölçekteki maddeler beşli Likert ölçeği ile ölçülmüsstür (1:kesinlikle katılmıyorum, 5:kesinlikle katılıyorum) ve ölçekte yedi boyut bulunmaktadır. Bunlar; liderlik 5 madde (VL1-VL5), sürekli gelişme 4 madde (VSG1-VSG4, çalışan tatmini 5 madde (VCT1-VCT5), eğitim-öğrenme 5 madde (VO1-VO5), süreç yönetimi 8 madde (VSY1-VSY8), işbirlikleri 8 madde (VI1-VI8) ve müşteri odaklılık 4 madde (VMO1-VMO4) şeklindedir. Anket formunun ikinci bölümünde demografik özellikler, üçüncü bölümünde ise çalışanların TKY ile ilgili düşüncelerini içeren ve evet/hayır şeklinde cevaplanan maddeler yer almaktadır. Burada yer alan maddeler çalışanların TKY'ye ne kadar yakın olduklarını ve TKY'nin kurumlarında kaliteli hizmet vermek için gerekli olup olmadıklarını belirlemeye yönelik maddelerdir. Elde edilen veriler SPSS 23 programı ile analiz edilmiştir.

\section{Bulgular}

Araştırmaya katılan toplam 187 çalışanın demografik özellikleri ve iş ile ilgili bilgileri Tablo 1.'de görülmektedir. Tablo 1.'de F sütunu frekansları, \%F sütunu kümülatif frekansları, Küm (\%) sütunu ise kümülatif \% frekansları göstermektedir. Katılımcılar arasında kadın erkek oranı aynı olmakla birlikte, evlilerin sayısı bekârlardan daha fazladır. Katılımcıların yarısı 33-40 yaş arasındadır ve yine yarısı lisans mezunudur. Katılımcıların çoğunluğu işletmede 4-6 yıldır çalışmaktadır ve yine çoğunluğu memur pozisyonunda çalışmaktadır. 
Tablo 1.

Katılımcıların Bilgileri

\begin{tabular}{|c|c|c|c|c|c|c|c|c|c|}
\hline & & $F$ & $F(\%)$ & Küm (\%) & & & $F$ & $F \quad(\%)$ & Küm (\%) \\
\hline \multirow{2}{*}{ Cinsiyet } & Kadın & 97 & 51,9 & 51,9 & \multirow{6}{*}{ Tecrübe } & 1 y1ldan az & 19 & 10,2 & 10,3 \\
\hline & Erkek & 90 & 48,1 & 100 & & $1-3$ y1l & 42 & 22,5 & 33,2 \\
\hline \multirow{2}{*}{ Medeni durum } & Evli & 113 & 60,4 & 60,4 & & $4-6$ yil & 58 & 31 & 64,7 \\
\hline & Bekâr & 74 & 39,6 & 100 & & $7-9$ y1l & 23 & 12,3 & 77,2 \\
\hline \multirow{3}{*}{ Yaş } & 32 ve alt 1 & 39 & 21 & 21 & & $10-12$ y1l & 11 & 5,9 & 83,2 \\
\hline & $33-40$ & 94 & 50,5 & 71,5 & & 13 y1l ve üstü & 32 & 16,6 & 100 \\
\hline & 41 ve üstü & 53 & 28,5 & 100 & \multirow{5}{*}{ Pozisyon } & Memur & 88 & 47,1 & 47,3 \\
\hline \multirow{4}{*}{ Eğitim } & İlköğretim & 29 & 16 & 16 & & Şef & 37 & 19,3 & 66,7 \\
\hline & Lise & 48 & 26,5 & 42,5 & & Müdür & 11 & 5,9 & 72,6 \\
\hline & Lisans & 95 & 52 & 95 & & Hizmetli & 20 & 10,7 & 83,3 \\
\hline & Lisansüstü & 10 & 5,5 & 100 & & Diğger & 31 & 16,6 & 100 \\
\hline
\end{tabular}

Kurumlarında kalite eğitimi alanlar veya kalite ile ilgili çalışmalara katılanların oranı kurumlarda TKY ile ilgili faaliyetlerin ne aşamada olduğu konusunda ipucu vermektedir. Tablo 2.' de görüldüğü gibi, TKY ile ilgili eğitim almış olan katılımcıların oranları kurum bazında \%55-\%68 arasındadır. Kurumun kalite çalışmalarına katılanların oranı ise daha düşüktür ve $\% 33-\% 45$ arasındadır. Bu durum bize kurumda hem eğitim anlamında hem de fiili olarak kalite çalışmaları anlamında önemli çaba gösterildiğini kanıtlamaktadır.

Tablo 2.

Katılımcıların kurumlar bazında kalite ile ilgileri

\begin{tabular}{lccccc}
\hline & Kurum & Kurum & Kurum & Kurum & Toplam \\
& 1 & 2 & 3 & 4 & $58 \%$ \\
\hline TKY ile ilgili eğitim alan & $57 \%$ & $55 \%$ & $60 \%$ & $68 \%$ & $51 \%$ \\
\hline Kurumun kalite çalışmalarına katılan & $43 \%$ & $33 \%$ & $45 \%$ & $43 \%$ & $41 \%$ \\
\hline
\end{tabular}

\section{Ölçeğinin Geçerlik ve Güvenirlik Çalışması Sonuçları}

Araştırmada kullanılan ölçeğin maddeleri ile ilgili tanımlayıcı istatistikler ve basıklık çarpıklık değerleri incelenmiştir. Çarpıklık değerlerinin -1,35 ile 1,146 arasında olduğu, basıklık değerlerinin tümünün $-1,27$ ile $+2,6$ aralığında olduğu görülmüştür. Basıklık değerlerinde $+1,5$ in üzerinde sadece üç değer bulunmaktadır.Verilerin Basklık çarpıklık değerlerinin $-1,5,+1,5$ arasında olması normal dağıldığına işarettir (Tabachnick ve Fidell, 2014).

Araştırmada kullanılan yedi boyutlu ölçeğin geçerliliği doğrulayıcı faktör analizi (DFA) ile incelenmiştir. DFA, ölçme modellerinin geliştirilmesinde kullanılan ve araştırmacılar için önemli kolaylıklar sağlayan bir analiz yöntemidir. DFA, geçerlilik analizlerinde kullanılmakta veya önceden belirlenmiş bir yapının doğrulanmasını amaçlamaktadır (Kline, 2011: 72). Bu çalışmada DFA, veri toplamak için kullanılan ölçme araçlarının var olan yapılarının korunup korunmadığını test etmek için kullanılmıştır. DFA analizi sonucunda bazı maddelerin faktör yüklerinin .33'ün altında 
değerler aldı̆̆1 anlaşılmıştır (L2, L4, SG2, CT1, O2, SY2, SY5, SY6, I2, I4, I6, I7 ve M4). Bu maddeler tek tek çıkarılarak DFA analizi tekrarlanmıştır. Nihai DFA sonunda elde edilen uyum değerleri incelenmiş ve uyum değerlerinden bazılarının kabul edilebilir düzeyde olmadığg anlaşılmıştır. Daha iyi uyum değerleri elde edilebilmek için modifikasyon indeks değerleri incelenmiş ve uygun maddelerin hataları arasındaki korelasyonlar serbest bırakılmıştır. Test edilen yedi faktörlü model Şekil 2.' de yer almaktadir.

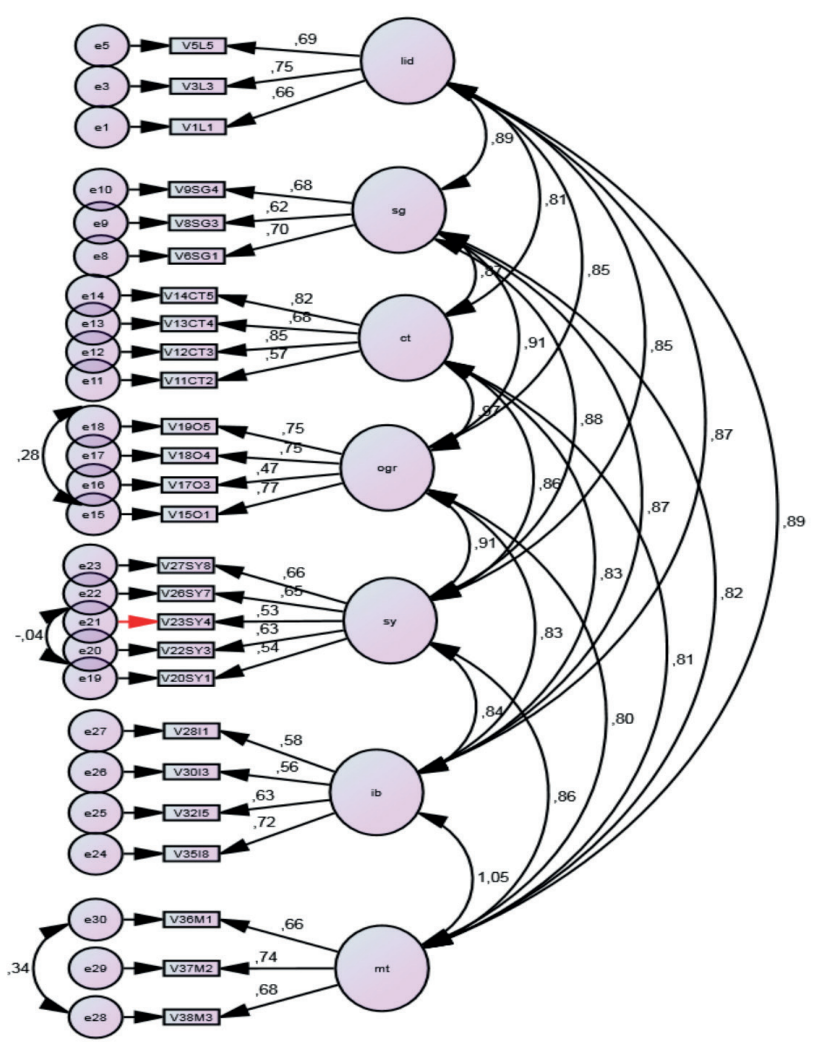

Şekil 2. Yedi faktörlü modele ait DFA

$\mathrm{Bu}$ işlemden sonra DFA tekrar gerçekleştirilmiştir. Modelin uyum değerleri Cmin/ $\mathrm{df}=1,67, \mathrm{GFI}=0,84, \mathrm{CFI}=0,92, \mathrm{RMSE}=0,60$ ve $\mathrm{SRMR}=0,50$ olarak elde edilmiştir. Test edilen yedi faktörlü modelin GFI dışında genel olarak kabul edilebilir düzeyde uyum değerlerine sahip olduğu anlaşılmıştır. GFI değeri de kabul edilebilir değer olan 0,85 değerine çok yakındır (Bollen, 1989; Browne ve Cudeck, 1993; Hu ve Bentler, 1999; Tanaka ve Huba, 1985). Modelin yedi faktörlü özgün yapısı korunmuştur. Modelde gösterilen tüm yollar istatistiksel olarak anlamlıdır $(p<0,01)$. DFA sonucunda Liderlik, Sürekli Gelişim, Çalışan Tatmini, Öğrenme, Süreç Yönetimi, İşbirlikleri ve Müşteri Odaklılık boyutlarında bulunan maddelerin faktör yükleri sırası ile. 66-.75, $.62-.71, .57-.82, .47-.77, .53-.66, .57-.72$ ve. 66-.74 arasında değerler almıştır. 


\section{Hipotezlerin Testi}

Hipotezlerin testi için oluşturulan ve Şekil 1.'de görülen yapısal model için öncelikle uyum değerleri ve ilişkilerin anlamlılığı incelenmiştir. Modelin uyum değerleri $\mathrm{Cmin} / \mathrm{df}=1,77, \mathrm{GFI}=0,84, \mathrm{CFI}=0,90, \mathrm{RMSE}=0,65$ ve $\mathrm{SRMR}=0,53$ olarak elde edilmiştir. Bu değerlerin GFI dışında uygundur, GFI'nın ise kabul edilebilir değer olan 0,85 değerine çok yakındır (Bollen, 1989; Browne ve Cudeck, 1993; Hu ve Bentler, 1999; Tanaka ve Huba, 1985). Elde edilen sonuçlar ve hipotezlerin desteklenip desteklenmediği Tablo 3.'de görülmektedir. Çalışan tatmini müşteri tatmini ilişkisi ( $p=0.152)$ dişındaki tüm ilişkiler ( $\mathrm{p}=0.001$ düzeyinde) anlamlı bulunmuştur. Bir başka ifade ile H8 dışındaki bütün hipotezler desteklenmiştir. Sonuçlar literatürle tutarlıdır. Anderson vd.'nin (1995) gerçekleştirdiği yol analizinde öğrenme süreç yönetimi ilişkisi ve sürekli gelişme müşteri tatmini ilişkisi anlamsız olarak bulunurken diğer ilişkiler anlamlı olarak elde edilmiştir. Brfield vd.'nin (2005) yol analizi ile gerçekleştirdiği çalışmada ise süreç yönetimi çalışan tatmini ve çalışan tatmini müşteri tatmini ilişkisi anlamsız olarak elde edilmiştir. Bu çalışma yol analizi ile de YEM ile gerçekleştirildiğinden sonuçlar tam olarak kıyaslanabilir olmasa da yolların anlamlılı̆̆ı açısından kıyaslama önemlidir.

Tablo 3.

Yaptsal model ile ilgili hipotezlerin sonuçlart

\begin{tabular}{lllllll}
\hline & & & & $\begin{array}{c}\text { Standardize } \\
\text { Regresyon } \\
\text { Katsayılar }\end{array}$ & $\begin{array}{c}\text { Standart } \\
\text { Hata }\end{array}$ & Kritik Oran \\
\hline $\mathrm{H}_{1}$ & öğrenme & $\leftarrow$ & liderlik & 0,881 & 0,134 & $8,00^{* *}$ \\
\hline $\mathrm{H}_{2}$ & işbirlikleri & $\leftarrow$ & liderlik & 0,911 & 0,104 & $7,50 * *$ \\
\hline $\mathrm{H}_{3}$ & süreç yönetimi & $\leftarrow$ & ogrenme & 0,63 & 0,088 & $4,62 * *$ \\
\hline $\mathrm{H}_{4}$ & süreç yönetimi & $\leftarrow$ & işbirlikleri & 0,428 & 0,113 & $3,49 * *$ \\
\hline $\mathrm{H}_{5}$ & sürekli gelişme & $\leftarrow$ & Süreçyönetimi & 0,997 & 0,19 & $6,37 * *$ \\
\hline $\mathrm{H}_{6}$ & çalışan tatmini & $\leftarrow$ & süreçyönetimi & 0,924 & 0,191 & $5,80 * *$ \\
\hline $\mathrm{H}_{7}$ & müşteri tatmini & $\leftarrow$ & sürekligelişme & 0,913 & 0,106 & $7,85^{* *}$ \\
\hline $\mathrm{H}_{8}$ & müşteri tatmini & $\leftarrow$ & çalışantatmini & $-0,478$ & 0,308 & 1,43 \\
\hline$* * 0,001$ düzeyinde anlamlıdır. & & & & & \\
\hline
\end{tabular}

Ölçeğinin güvenirliği Cronbach Alfa iç tutarlık katsayıları hesaplanarak incelenmiştir. Elde edilen sonuçlar Tablo 4.'de gösterilmiştir. Tablo 4'e göre, ölçek faktörlülerinin iç tutarlıklarının yeterli düzeyde olduğunu anlaşılmıştır (Durmuş, 2011: 89).

Tablo 4.'de ayrıca faktör ortalamaları ve standart sapmaları da görülmektedir. Çalışanların en olumlu algıladıkları faktörler sırası ile; müşteri tatmini ve çalışan tatmini, öğrenme, süreç yönetimi, işbirlikleri, sürekli gelişme ve liderlik şeklindedir. Faktörler ile ilgili algılamaların kurum bazında değişip değişmediği $\left(\mathrm{H}_{9}\right)$ Kruskal- 
Tablo 4.

TKY ile ilgili faaliyetleri ölçmeye yaran TKY Ölçeğinin Faktörlerinin Tanımlayıcı İstatistikleri ve İç Tutarlık Katsaylarl

\begin{tabular}{lcccc}
\hline Faktör & Madde Sayisl & Ortalama & Std. Sapma & Cronbach's $\alpha$ \\
\hline Liderlik & 3 madde & 3,78 & 0,71 & 0,74 \\
\hline Sürekli Gelişme & 3 madde & 3,85 & 0,69 & 0,71 \\
\hline Çalışan Tatmini & 4 madde & 3,9 & 0,75 & 0,81 \\
\hline Öğrenme & 4 madde & 3,89 & 0,75 & 0,8 \\
\hline Süreç Yönetimi & 5 madde & 3,87 & 0,63 & 0,74 \\
\hline İşbirlikleri & 4 madde & 3,86 & 0,6 & 0,72 \\
\hline Müşteri Tatmini & 3 madde & 3,9 & 0,63 & 0,78 \\
\hline
\end{tabular}

Wallis testi ile analiz edilmiştir. Analiz sonuçlarına göre anlamlılık düzeyleri sıras1 ile liderlik $(p=0,22)$, sürekli gelişme $(p=0,36)$, çalışan tatmini $(p=0,36)$, öğrenme ( $p=0,51)$, süreç yönetimi $(p=0,43)$, işbirlikleri $(p=0,66)$ ve müşteri tatmini $(p=0,38)$ şeklindedir ve hiçbir faktör için anlamlı bir farklılık gözlemlenmemiştir. Dolayısı ile kurumlar arsında TKY uygulamalarının algılanması bakımından bir farklılık bulunmamaktadır. Katılımcıların yaklaşık yarısını oluşturan ve araştırma yapılan kurumlar içinde ISO 9001 ve ISO 27000 sertifikalarına sahip tek kurum olan Kurum 1.'de çaışanların algılamaları ile diğer kurumlarda çalışanların algılamaları arasında anlamlı bir farklılık bulunmamıştır.

Kurumda çalışanların çalıştıkları pozisyon açısından faktörleri algılamaları arasında bir farklılık olup olmadığ $\left(\mathrm{H}_{10}\right)$ Kruskal-Wallis testi ile analiz edilmiş̧ir. Tüm faktörler için pozisyonlar açısından $\% 5$ düzeyinde anlamlı bir farklılık gözlemlenmiştir. Farklılıkların hangi pozisyonlar arasındaki farklılıktan kaynaklandığını belirlemek için her faktör için tüm pozisyonlar arasında Mann-Whitney U testi gerçekleştirilmiştir. Memur şef ve müdürler arasında bir farklılık görülmez iken, bu üç pozisyondakiler ile hizmetliler arasında ve diğer sınıfındaki çalışanlar arasında önemli farklılıklar gözlemlenmiştir. Burada hizmetlilerin ve diğer olarak yansıtılan taşeron çalışanların müdür şef ve memur grubu ile farklılaşması beklenen bir durumdur.

TKY'nin kamu kurumlarına uygun olup olmadığı konusunda ve TKY uygulamalarının kaliteli hizmet vermek için gerekli olup olmadığı konusunda farklı görüşler bulunmaktadır. Üstüner ve Coşkun (2004) TKY’yi Türkiye kamu sektörü için gerekli görenlerin oranı iki farklı kamu kurumunda $\% 85$ ve $\% 90$ olduğunu belirtirken, Çetin ve Özçakar (2014) ise TKY'yi kurumunda kaliteli hizmet vermek için gerekli görenlerin oran $1 \% 60$ olarak belirtmiştir. Bu çalışmada oran kurumlara göre $\% 80$ ila $\% 88$ arasında değişmekle beraber ortalama olarak \%83 seviyesinde çıkmıştır.

TKY'nin kaliteli hizmet vermek için gerekliliği konusundaki düşünce ile Kurumda TKY eğitimi almış olmak arasında bir ilişki olup olmadığı Kendall tau- B ile test 
edilmiştir (H11). Analiz sonucunda \%5 düzeyinde anlamlı bir ilişki bulunamamıştır $(p=0,074)$. TKY'nin kaliteli hizmet vermek için gerekliliği konusundaki düşüncenin TKY eğitimi ile ilişkili olduğu söylenemez. Bu düşüncenin kalite çalışmalarına katılmış olmak ile iliş̧kili olup olmadığ incelenmiştir $\left(\mathrm{H}_{12}\right)$. Analiz sonucunda \%5 düzeyinde anlamlı bir ilişki bulunamamakla birlikte değer $\% 5$ 'e çok yakındır $(p=0,053)$.

\section{Sonuç ve Tartışma}

Literatürde TKY'nin kamu sektöründeki durumu üzerine yapılan çalışmalar özel sektördeki çalışmalara göre daha sınırlıdır. Bu çalışmada dört farklı kamu kurumundaki uygulamalar, TKY'nin Deming Yönetim Metodu perspektifinden değerlendirerek analiz edilmiştir. Çalışmanın bulgularına göre öncelikle ölçek DFA ile analiz edilerek ölçeğin güvenilirlik ve geçerlilik açısından uygun olduğu görülmüştür. DFA sonunda yedi boyutlu orijinal ölçek yapısı bazı maddeler çıkarılarak korunmuştur. Modelin uygulanması sonucunda çalışan tatmini ile müşteri tatmini arasındaki yol dışında diğer tüm yollar anlamlı çıkmıştır. Bu durum literatür ile uyumludur aynı modeli kamu kurumlarının da içinde bulunduğu bir örneklemde kullanan Barfield vd.'nin (2005) yol analizi ile gerçekleştirdiği çalışmada süreç yönetimi çalışan tatmini ve çalışan tatmini müşteri tatmini ilişkisi anlamsız olarak elde edilmiştir. Buna göre Anderson vd. 'nin (1995) Deming Yönetim Metodu olarak değerlendirdikleri yol modeli, Türkiye Kamu sektöründeki dört kurum açısından DFA ve yapısal regresyon modeli ile incelenmiş ve anlamlı sonuçlar elde edilmiştir. Dolayısı ile liderlik ile başlayacak kalite yolculuğu eğitim öğrenme, işbirlikleri ile davam ederek, süreçlerle yönetim ve sürekli gelişme vasıtası ile müşteri tatmini sağlanabilecektir.

Çalışanların en olumlu algıladıkları faktörler sırası ile; müşteri tatmini ve çalışan tatmini, öğrenme, süreç yönetimi, işbirlikleri, sürekli gelişme ve liderlik şeklinde bulunmuştur. Boyutların algılanması açısından kurumlar arasında istatistiki olarak anlamlı bir farklılık gözlemlenmemiştir.

Çalışanların \%83'ü TKY'nin kurumlarında kaliteli hizmet vermek için gerekli olduğunu düşünmektedirler. TKY'nin kaliteli hizmet vermek için gerekliliği konusundaki düşüncenin, kurumda TKY eğitimi almış olmak ya da kurumda kalite ile ilgili çalışmalara katılmış olmakla ilişkili olmadığı belirlenmiştir. Dolayısı ile eğitimlere ya da çalışmalar katılsın ya da katılmasın çalışanlar genel olarak TKY'nin kamu sektörü için gerekli olduğunu düşünmektedirler.

Modelin sadece dört adet kamu kurumunda gerçekleştirildiğinden sonuçların genellemesi mümkün değildir. Sonraki çalışmalar daha büyük örneklemler ile gerçekleştirilerek Türkiye Kamu Sektörü için genelleme yapılabilir. 


\section{Kaynakça/References}

Acar, A., Sevinç, İ. (2013), Toplam Kalite Yönetiminin Kamu Sektörüne Uygulanmasına İlişkin Sorunla, Sosyal Ekonomik Araştırmalar Dergisi, (25), 1-16.

Anderson, J. C., Rungtusanatham, M., \& Schroeder, R. G. (1994), A theory of quality management underlying the Deming management method. Academy of Management Review, 19(3), 472509.

Anderson, J. C. Rungtusanatham, M., Schroeder, R. G. and Sarvanan, D. (1995), A path analytic model underlying the deming management method: preliminary empirical findings. Decision Sciences, 26(5), 637-658.

Aslan, C., (2017), Toplam Kalite Yönetimi Perspektifinde Eğitim ve Okul Kütüphanelerinin Organizasyonu Üzerine Bir İnceleme. Türk Kütüphaneciliği, 31(2), 251-258.

Aslantekin, F., Göktaş, B., Uluşen, M., \& Erdem, R., (2007), Sağlık hizmetlerinde kalite deneyimi: Dr. Ekrem Hayri Üstündağ kadın hastalıkları ve doğum hastanesi örneği. Fırat Sağlık Hizmetleri Dergisi, 2(6), 55-71.

Ayaz, H., \& Soykan, A. (2002), Toplam kalite yönetimi ve sağl1k sektörü. Turkiye Klinikleri Journal of Psychiatry, 3(1), 19-26.

Balc1, A. (2005a), Kamu örgütlerinde toplam kalite yönetimi uygulanması: Olumlu perspektifler ve olası zorluklar. S.Ü. Karaman İktisadi ve İdari Bilimler Fakültesi Dergisi, ss.196-211.

Balcı, A. (2005b). Kamu yönetiminde çağdaş yaklaşımlar ve kamu hizmet sunumuna etkileri, "Kamu yönetiminde ve kamu hizmetlerinde kalite" içinde, C.C. Aktan ve U. Saran (editörler), Ankara: Hizmet-İş Sendikası Yayını, ss. 19-38.

Barfield, J., Fisher, C. M., Li, J., \& Mehta, R. (2005). Retesting a model of the Deming management method. Total Quality Management and Business Excellence, 16(3), 401-412.

Fisher, C. M., Barfield, J., Li, J., \& Mehta, R. (2005). Retesting a model of the Deming management method. Total Quality Management and Business Excellence, 16(3), 401-412.

Bollen, K. A. (1989), A new incremental fit index for general structural equation models. Sociological Methods \& Research, 17(3), 303-316.

Boyne, George A. ve Walker Richard M., (2002), Total quality management and performance, Public Performance and Management Review, 26(2), s. 394.

Browne, M. W., \& Cudeck, R. (1993). Alternative ways of assessing model fit. Sage Focus Editions, $154,136-136$.

Bütün, H., \& Aslanargun, E. (2016), Mesleki ve teknik eğitim kurumlarında toplam kalite yönetimi uygulamalarının değerlendirilmesi. Anatolian Journal of Educational Leadership and Instruction, 4(1), 40.

Can, A. (2008), Örgüt kültürünün hastanelerde toplam kalite yönetimi uygulamalarına uygunluğunun testine yönelik bir araştırma. Süleyman Demirel Üniversitesi, İktisadi İdari Bilimler Fakültesi Dergisi, 13, s.293-307.

Çetin, N. (2008), Kuramsal liderlik çözümlemelerinin 1şığında, okul müdürlüğü ve eğitilebilir durumsal liderlik özellikleri. Pamukkale Üniversitesi Eğitim Fakültesi Dergisi, 1(23), 74-84.

Çetin, O. ve Özçakar, N. (2014), kamu sektöründe toplam kalite yönetimi: bir kamu kurumunda ampirik bir araştırma, Marmara Üniversitesi İ.İ.B. Dergisi, 36(1), ss. 351-372.

Çukurçayır, M. A. ve Sipahi, E.B. (2003), Yönetim yaklaşımı ve kamu yönetiminde kalite. Sayıştay Dergisi, 50-51, ss. 35-66. 
Dağlı, Y. (2014), Toplam kalite yönetiminin eğitim sistemine uygulanabilirliği. Elektronik Sosyal Bilimler Dergisi, 2.

Dean, J., W., Bowen, D. E. (1994), Management theory and total quality: Improving research and practice through theory development. Academy of Management Review, 19(3), s.392-418.

Durmuş, B., Yurtkoru, E.S. ve Çinko, M. (2011), Sosyal Bilimlerde SPSS ile Veri Analizi, İstanbul, Beta.

Ekinci, F. (2008), Kamu personel yönetiminden insan kaynakları uygulamasına geçişin çalışanların verimliliğine etkisi. Maliye Dergisi, 155, ss. 175-185.

Grandzol, J., Gershon, M. (1998), A survey instrument for standardizing tqm research. International Journal of Quality Service, 3(1), s.80-105.

Güller, H. (2008), Kamuda toplam kalite yönetiminin uygulanabilirliği: türkiye büyük millet meclisi'nde toplam kalite yönetimi perspektifiyle başlatılan çalışmaların incelenmesi (Yüksek Lisans Tezi), Ankara Üniversitesi Sosyal Bilimler Enstitüsü, Ankara, 2008.

Hasan, M., \& Kerr, R. M. (2003), The relationship between total quality management practices and organisational performance in service organisations. The TQM Magazine, 15(4), 286-291.

Hsieh, A. T., Chou, C. H., \& Chen, C. M. (2002), Job standardization and service quality: a closer look at the application of total quality management to the public sector. Total quality management, 13(7), 899-912.

Hu, L. T., \& Bentler, P. M. (1999), Cutoff criteria for fit indexes in covariance structure analysis: Conventional criteria versus new alternatives. Structural Equation Modeling: A Multidisciplinary Journal, 6(1), 1-55.

Kağnıcıoğlu, H., (2002), günümüz işletmelerinin yaşam anahtar: müşteri odaklılık. Ege Akademik Bakış Dergisi, 2(1), ss. 78-90.

Kazan, H , Değermen, A , Yurtman, G . (2017), Toplam kalite yönetiminin iç ve dış müşterilern performans değerlendirmesi üzerine etkisi. Yönetim ve Ekonomi Araştırmaları Dergisi, 15(1), 43-65.

Kline, R. (2011), Principles and Practice of Structural Equation Modelling, Guilford Press.

Madsen, O. N. (1995), Public enterprise and total quality management. Total Quality Management, $6(2), 165-174$.

Morgan, C., Murgatryod, S. (1994), Total Quality Management in the Public Sector, USA, Open University Press, 1994.

Özçakar, N., (2010), Bir kamu kuruluşundaki toplam kalite yönetimi uygulamalarının değerlendirilmesi. İstanbul Üniversitesi İşletme Fakültesi Dergisi, 39(1), ss. 106-124.

Özsalmanlı, A. Y. (2005), Türkiye'de kamu yönetiminde liderlik ve lider yöneticilik. Manas Üniversitesi Sosyal Bilimler Enstitüsü Dergisi, 13, s. 137-146.

Prajogo, D. (2005), The Comparative Analysis of TQM Practices and Quality Performance between manufacturing and service firms. International Journal of Service Industry Management, 16-3.

Peker, Ö. (1996), Toplam kalite yönetimi ve kamu hizmetlerinde toplam kalite. Çağdaş Yerel Yönetimler Dergisi, 5(2), ss. 41-57.

Powell, T. (1995), Total quality management as competitive advantage: A review and empirical study. Strategic Management Journal, 16. 
Scharitzer, D. \& Korunka, C. (2000), New public management: Evaluating the success of total quality management and change management interventions in public services from the employees' and customers' perspectives. Total Quality Management, 11(7), 941-953.

Tabachnick, B. G. ve Fidell, L. S. (2014), Using multivariate statistics. Allyn ve Bacon/Pearson Education.

Tanaka, J. S., \& Huba, G. J. (1985), A fit index for covariance structure models under arbitrary GLS estimation. British Journal of Mathematical and Statistical Psychology, 38(2), 197-201.

Üstüner, Y., Coşkun, S. (2014), Quality Management in the Turkich Public Sector: A survey. Public Administration Development, 24, s. 157-171.

Yaş, S. Z. (2009), Toplam kalite yönetimi anlayışının sağlık sektöründe uygulanması: Trakya Üniversitesi Sağlık Araştırma ve Uygulama Merkezi ile Edirne Devlet Hastanesi'nin karşılaştırılması. (Yayınlanmamış Yüksek Lisans Tezi), Trakya Üniversitesi SBE.

Yunus, T. A. Ş., AKPINAR, A. T., \& Emre, İ. Ş. Ç. İ. (2016), The effects of quality management system on patient safety culture in hospitals. Siyaset, Ekonomi ve Yönetim Araştırmaları Dergisi, 4(2). 
